\title{
Outcomes of the round robin tests of RILEM TC 247-DTA on the durability of alkali-activated concrete
}

\author{
John L. Provis ${ }^{1}$ and Frank Winnefeld ${ }^{2, *}$ \\ ${ }^{1}$ Department of Materials Science and Engineering, The University of Sheffield, Sheffield, S1 3JD, United Kingdom \\ ${ }^{2}$ Empa, Swiss Federal Laboratories for Materials Science and Technology, 8600 Dübendorf, Switzerland
}

\begin{abstract}
Alkali-activated cements, including 'geopolymer' materials, are now reaching commercial uptake in various parts of the world, providing the opportunity to produce concretes of good performance and with reduced environmental footprint compared to established technologies. The development of performance-based specifications for alkali-activated cements and concretes is ongoing in several jurisdictions. However, the technical rigour, and thus practical value, of a performance-based approach to specification of novel cements and concretes will inevitably depend on the availability of appropriate, reliable testing methods, particularly regarding key aspects of durability where degradation mechanisms may be complex and depend on the chemistry and microstructure of the binder. This paper will briefly discuss the activities of RILEM Technical Committee 247-DTA in working to validate durability testing standards for alkali-activated materials, bringing scientific insight into the development of appropriate specifications for these materials.
\end{abstract}

\section{Introduction}

Concrete is the world's most widely used material. The production of Portland cement, the main binder of concrete nowadays, amounted to $4.6 \mathrm{Gt}$ in 2016 [1] and contributes approximately $8 \%$ of all anthropogenic $\mathrm{CO}_{2}$ emissions [2,3]. The global average of $\mathrm{CO}_{2}$ emissions for the manufacture of Portland cement clinker is estimated to be $866 \mathrm{~kg} / \mathrm{t}$ [4], with about $60 \%$ originating from the decarbonation of limestone while the major part of the remaining $40 \%$ is due to the combustion of carbon-rich fuels. To make Portland cement, the clinker is blended with calcium sulfate set regulator and generally other mineral constituents, i.e. (limestone) fillers and supplementary cementitious materials such as blast furnace slag or fly ash. Because such materials have lower $\mathrm{CO}_{2}$ footprints that the Portland cement clinker, the global average $\mathrm{CO}_{2}$ footprint of Portland cement is estimated to be $660 \mathrm{~kg} / \mathrm{t}$ [4]. By increasing the use of supplementary cementitious materials this value can be potentially reduced further, however values below $500 \mathrm{~kg} / \mathrm{t}$, assuming a realistic target for the clinker factor of approximately $60 \%$, appear to be unlikely [5].

When the $660 \mathrm{~kg} \mathrm{CO} 2$ per $\mathrm{t}$ of Portland cement are recalculated to an average concrete mix design, the $\mathrm{CO}_{2}$ footprint of $1 \mathrm{t}$ of concrete can be calculated to approximately $80-90 \mathrm{~kg} \mathrm{CO}$. This value appears quite low compared to e.g. steel, which is associated to a $\mathrm{CO}_{2}$ footprint between 600 and $2200 \mathrm{~kg} / \mathrm{t}$ (the lower value refers to recycled steel) [6]. However, in the case of Portland cement-based concrete, the vast amounts produced worldwide, which are estimated to increase strongly in coming years [7], are responsible for the high overall share of the anthropogenic $\mathrm{CO}_{2}$ emissions.

Because of this, the reduction of $\mathrm{CO}_{2}$ emissions associated with the manufacturing of concrete has been the main driver of research and innovation in the field of cementitious materials in the recent years. The activities include blended Portland cements [8,9], cements based on innovative clinker types [10], as well as non-clinker based cements such as alkali-activated materials ("AAM") [11], which will be the main focus of this paper.

It is essential not only to use better cements, but also to use cements better: concretes must be designed for durability [12] and without excessively high cement content $[13,14]$. Nonetheless, it is essential to improve efficiency at every step in the cement and concrete value chain, and this requires that new and innovative cements are developed, tested and validated. In order to meet $\mathrm{CO}_{2}$ emission targets, many different solutions based on locally available materials and technologies will be required, rather than a global new technology of cement production. Portland cement-based concrete will, due to the global availability of its raw materials, be the dominant technology also in the future, using cements containing increasing amounts of supplementary cementitious materials $[9,15,16]$.

AAM are, along with other cementitious materials such as supersulfated slag cements or calcium sulfoaluminate cements [17], potential alternatives to Portland cement. They combine potentially high $\mathrm{CO}_{2}$ savings of $60-90 \%$ compared to plain Portland cements [18] and use of industrial by-products, with good

* Corresponding author: frank.winnefeld@empa.ch 
performance in engineering properties such as high compressive strength and the possibility to achieve high durability [11]. On a local basis, the availability of suitable precursors for alkali-activated cements (e.g. fly ash in countries which use coal for electricity generation, or clays or metallurgical slags in other locations) is often high $[19,20]$, and activators can in most regions be sourced in sufficient volumes to enable AAM to be produced and used in a meaningful way.

\section{Towards standardization of AAM}

In order to foster further application of concrete based on alternative cements such as AAM, it is essential to undertake research and development related to a deeper understanding of suitable raw materials, mix design, hydration mechanisms, mechanical properties, durability etc., which form the basis of standardization [21-25].

Early progress in standardization of AAM was made in the former Soviet Union, where numerous standards had been developed in the past decades [26, 27]. However, the majority of these are prescriptive in nature and this is an approach which is very difficult to scale to a diverse set of raw materials for deployment of AAM technology in different regions and scenarios. To achieve this, performance-based specifications are essential.

As a world-leading step in this direction, the British Standards Institute has released a Publicly Available Specification, PAS 8820:2016 [28], which defines a performance-based testing approach to enable the use of innovative materials without imposing detailed restrictions on cement selection or mix design. This contrasts with the very prescriptive approach embodied in the current British Standards for concrete, e.g. BS 8500 [29]. The PAS 8820 protocol parallels to some degree the Equivalent Durability Procedure [30] which is applied in many European nations alongside the EN 206 concrete standard [31]; more details are given in [32].

In Switzerland the National Guideline SIA MB 2049 [33] gives a procedure for the national approval of alternative cements for structural concrete, which are not covered by the EN 197-1 cement standard [34]. The approach is also based on an equivalent performance approach using reference concretes. Besides blended Portland cements outside the specifications of EN 197-1, activated slag cements (AAM and supersulfated cement) are also covered by this Guideline for use in Switzerland.

However, the reference concrete method is based on the assumption that a performance level measured in a given laboratory test will correspond to a similar level of field performance, when comparing concretes of different chemistry and thus microstructure (e.g. Portland-based and alkali-activated concretes). This may not be wholly true, particularly for accelerated tests in which the test conditions differ significantly from those found in a natural exposure environment, e.g. accelerated carbonation at high $\mathrm{CO}_{2}$ concentrations [35], or estimation of chloride transport from measurements of the electrical properties of the concrete [36].

Ongoing work in RILEM Technical Committee 247DTA, including a recently-concluded round robin testing programme which assessed the validity of different durability testing methods as applied to alkali-activated concretes, is intended to support and enable engineers to select the most appropriate tests for such specifications.

\section{Round robin tests of RILEM TC DTA}

\subsection{Overview}

Through a round-robin testing programme conducted by RILEM Technical Committee 247-DTA since 2012, an interlaboratory comparison of various accelerated and non-accelerated durability tests applied to AAM concretes has been undertaken. This has involved investigation of various available methods to determine chloride ingress, sulfate attack, carbonation, alkali-silica reaction, and freeze-thaw/frost-salt processes.

The selected test methods were applied to concretes produced by alkali-activation of ground granulated blast furnace slag (GGBFS), siliceous fly ash (FA), or flashcalcined metakaolin (MK). Each of these precursors was activated by blending it with sodium silicate solution (mixed to the same composition from locally-obtained constituents), and each precursor powder was sourced from a single supplier and shipped to all test participants. Each participant used local aggregates and established laboratory practice for mixing and casting concretes. For the slag-based and fly ash-based mixes, concretes were designed to achieve 'high' and 'moderate' performance levels for each precursor, with the concept that the round-robin test would enable TC members to define whether the testing methods were able to distinguish between the performance levels of these different mixes. Table 1 summarizes the concrete mix designs used.

Table 1. Mix designs of the AAM concretes used

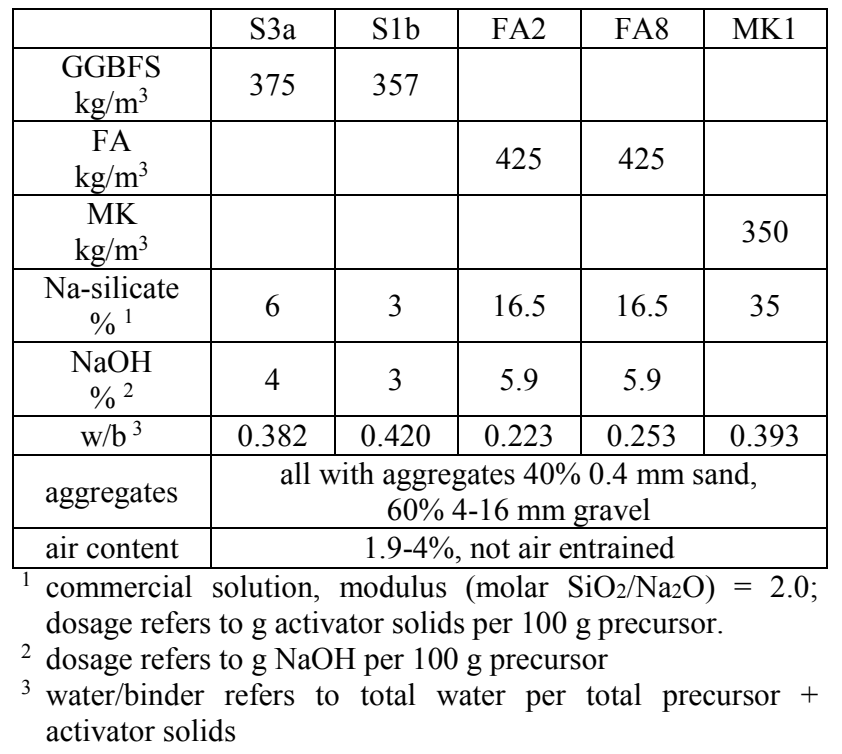

The focus of the work of this TC was not to identify which of the alkali-activated materials shows higher performance under given conditions, or to prove anything in particular about the durability of AAM in general. Rather, the focus is to 'test the tests', and to 
understand whether the established methodologies designed for accelerated durability testing of Portland cement-based concretes can actually give meaningful outcomes when applied to these non-Portland materials.

The round-robin work of RILEM TC 247-DTA is nearing its conclusion. In total 19 labs from 12 different countries have returned results. The following sections present selected findings from the preliminary evaluation of the test results.

\subsection{Strength and workability}

Fig. 1 shows that the round robin test participants identified significant variability in strength (and also in workability; data not shown) between alkali-activated concrete mixes produced in different laboratories using the same binder but different aggregates. However, the within-laboratory reproducibility of these characteristics was in general very good. A small number of laboratories found some of the mixes to be unworkable for casting and so reported zero or very low strengths; these results are not shown, as all other laboratories observed acceptable rheology.

\subsection{Chloride penetration}

For testing chloride penetration, NordTest NT Build 443 (ponding test) [37], NordTest NT Build 492 (electrically accelerated migration test) [38] and ASTM C1202 (RCPT - charge passed test) [39] were selected.

The differences in strength results between laboratories are not paralleled by the differences in performance levels in durability tests. Durability performance appears to relate more closely to basic mix design parameters than to strength. Fig. 2 highlights this observation using the accelerated chloride migration coefficients determined for the two alkali-activated blast furnace slag concretes from Table 1 (S3a of high designed performance, $\mathrm{S} 1 \mathrm{~b}$ of moderate designed performance); the chloride migration coefficients clearly do not correlate to the compressive strengths obtained for the same concrete mixes in the same laboratories.

In fact, for the slag-based mixes in this test programme, mix S1b designed for 'moderate' performance on average outperformed the higherstrength mix $\mathrm{S} 3 \mathrm{a}$ in both chloride diffusion and migration tests, possibly because its higher strength was achieved in part via a higher paste volume. Most prescriptive standards and codes assume that compressive strength and durability performance should correlate directly, although this has long been known to be incorrect and misleading [40]. Neville [40] noted that the correlation between 28-day compressive strength and durability was probably acceptable for concretes produced up to 1970 , but not since then as concrete technology and cement chemistry (including the use of blended cements) have improved. The extension of the definition of 'concrete' (in the context of standardization) to include alternative binders, including but not limited to AAM, means that the relationships for these materials will deviate even further from the historical assumption of correspondence between strength and durability across a broad range of materials, and this is supported by the results of this RILEM roundrobin test.

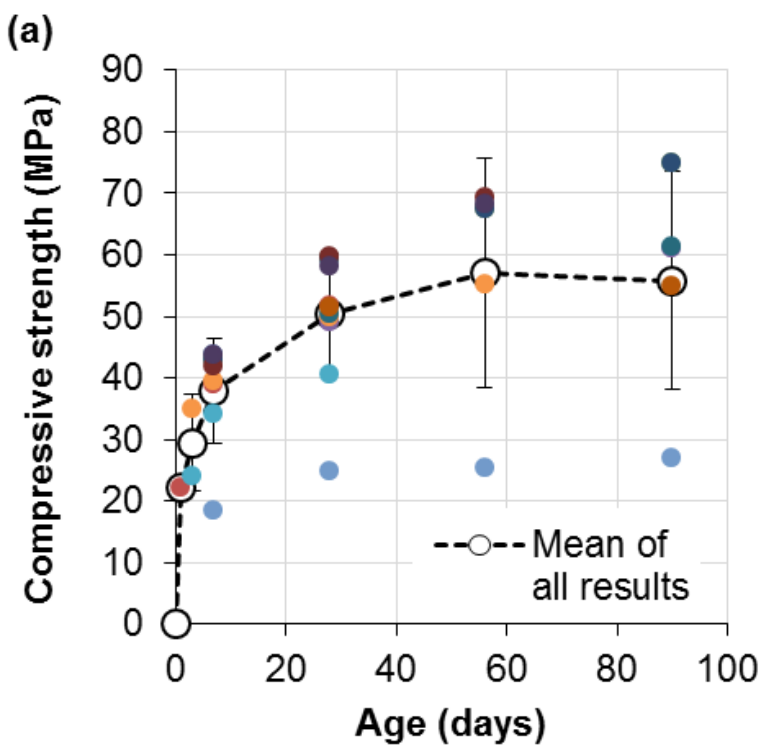

(b)

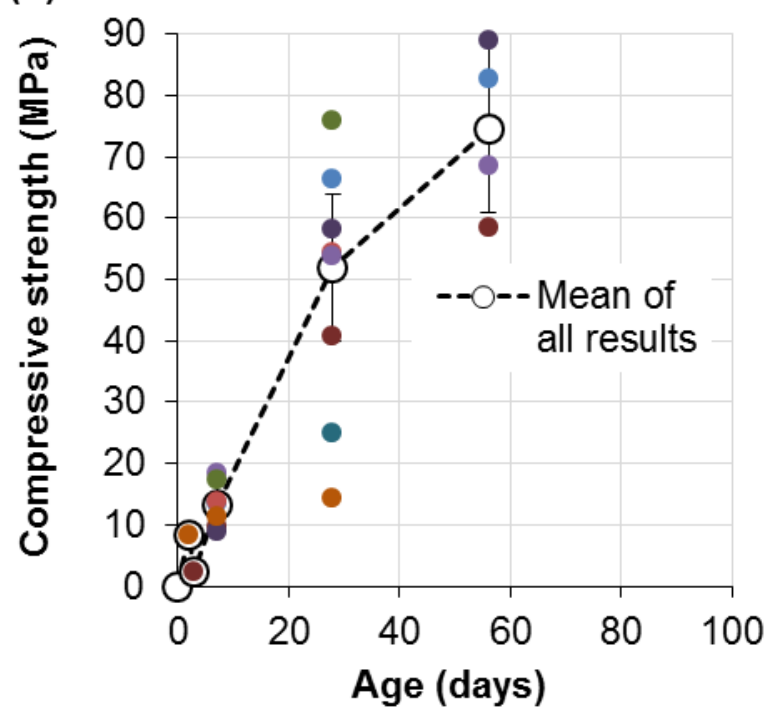

Fig. 1. Compressive strength test results from participating laboratories in the round-robin test: (a) concrete mix S3a based on ground granulated blast furnace slag; (b) concrete mix FA2 based on fly ash. In each case, each individual point represents a single sample, colour-coded by the identity of the lab that conducted the test. All concretes in each set have the same binder composition and mix design, but were produced with locally available aggregates, targeting as similar a grading curve as was feasible. The dashed line represents the mean of all results received, with error bars showing one standard deviation either side of this mean. 


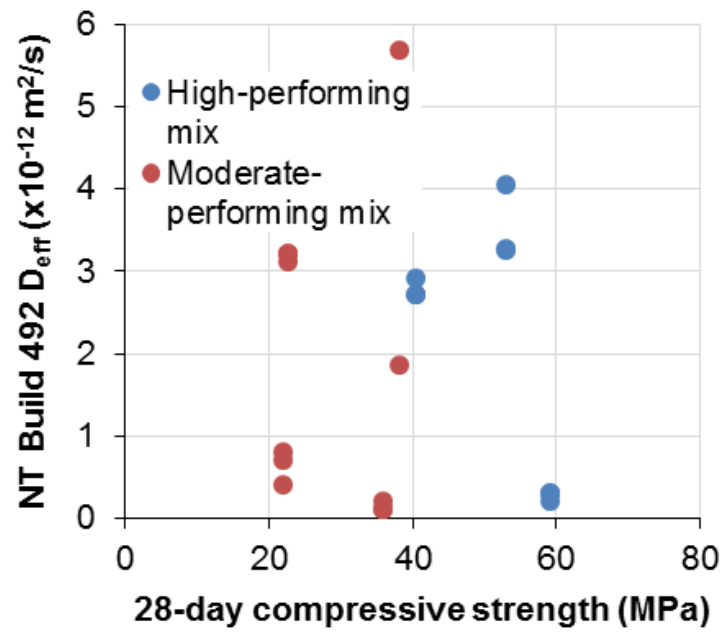

Fig. 2. Comparison between 28-day compressive strength and 28-day effective chloride migration coefficients obtained from the NordTest NT Build 492 electrically accelerated method [38], for the high- and moderate-performing alkali-activated concretes based on ground granulated blast furnace slag (S3a and $\mathrm{S} 1 \mathrm{~b}$, respectively), in four different laboratories.

The chloride diffusion and migration tests examined in this round-robin test (NordTest methods 443 and 492, respectively) generally rank the various concretes in Table 1 in the same order from both tests. There is some interlaboratory scatter between the actual diffusion or migration coefficients determined, but within-laboratory reproducibility of both tests appears acceptable. However, the ASTM C1202 "rapid chloride penetration test" did not give such favourable outcomes; this method is not at all recommended for testing of AAM as it gives scattered and unreliable results, as shown in in Fig. 3.

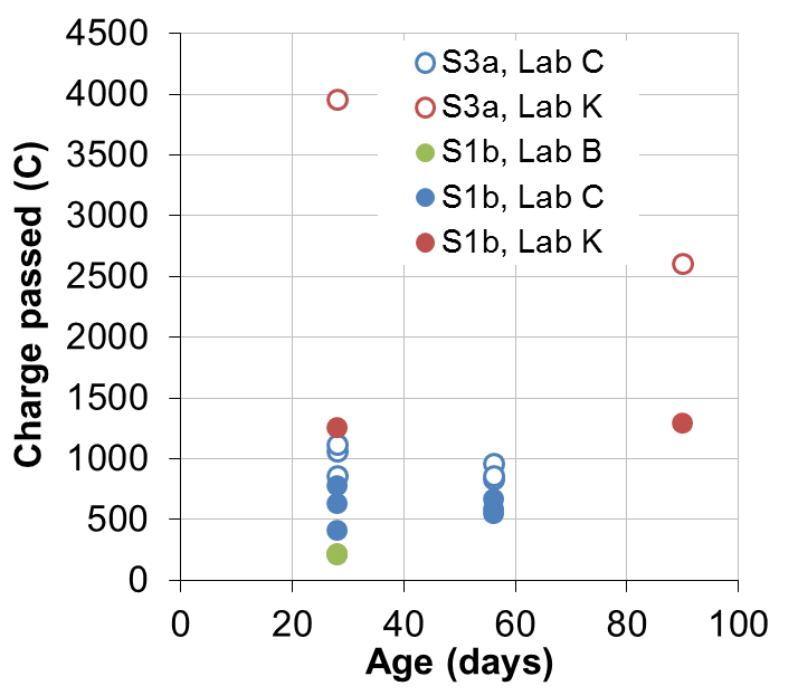

Fig. 3. ASTM C1202 [39] charge passed results obtained in three different laboratories for multiple replicate samples of the two different alkali-activated concretes based on alkaliactivated slag in Table 1, designed for 'high' (S3a) and 'moderate' (S1b) performance levels, measured at different ages.

Fig. 3 does not show any consistent trend or alignment of test results between participating laboratories. The only apparent point of similarity between laboratories was that in the majority of cases (but not uniformly), the 'high performance' alkali-activated slag concrete mix S3a, which has both a high paste volume and a high activator dose (Table 1), allowed more charge to pass (which would be taken to indicate a higher chloride permeability) than did the concrete of moderate performance. This is consistent with the results in Fig. 2 from accelerated migration testing, and shows that the higher alkali content of the pore solution of the highperforming concrete influences the conductivity of these concretes.

Other than this, it is not possible to extract useable information in the data presented in Fig. 3, as both the within-laboratory and interlaboratory comparisons are too scattered to be meaningful, and the pore refinement that is known to take place by extended curing of alkaliactivated slag paste [41] is not reflected in the chargepassed data. Thus, the validity of application of the ASTM C1202 test to alkali-activated concretes appears questionable.

\subsection{Carbonation}

Fig. 4 shows the carbonation depths measured in alkaliactivated slag concrete $\mathrm{S} 1 \mathrm{~b}$, under both natural and accelerated $\left(1 \% \mathrm{CO}_{2}\right)$ carbonation exposure. It should be noted that, all samples tested for carbonation were cured sealed in polymeric film or bags for $28 \mathrm{~d}$ before the start of carbonation exposure.

The reproducibility of the results shown in Fig. 4 is very good considering that: (a) the concretes produced in different laboratories differed significantly in compressive strength, as discussed above (Fig. 2); and (b) Fig. 4a includes data for natural carbonation that were collected both indoors and under sheltered outdoor conditions. For comparison, Aït-Mokhtar et al. determined coefficients of variation of $12-37 \%$ in the rates of accelerated $\left(50 \% \quad \mathrm{CO}_{2}\right)$ carbonation of industrially-produced blended Portland cement concretes sourced from a single batch [42].

Accelerated carbonation testing at a concentration of $1 \% \mathrm{CO}_{2}$ appears to provide an acceptable compromise between maintaining realistic chemical effects (and thus trends in the ranking of samples) in alkali-activated concretes, and the need to obtain a useful test result (readily measurable carbonation depth) in a sensible timeframe. The trends in carbonation rates at $1 \% \mathrm{CO}_{2}$ between AAM concretes produced with the same precursor and high vs. moderate design performance levels were consistent with these design performance levels, and also matched the rankings based on natural carbonation data. 
(a)
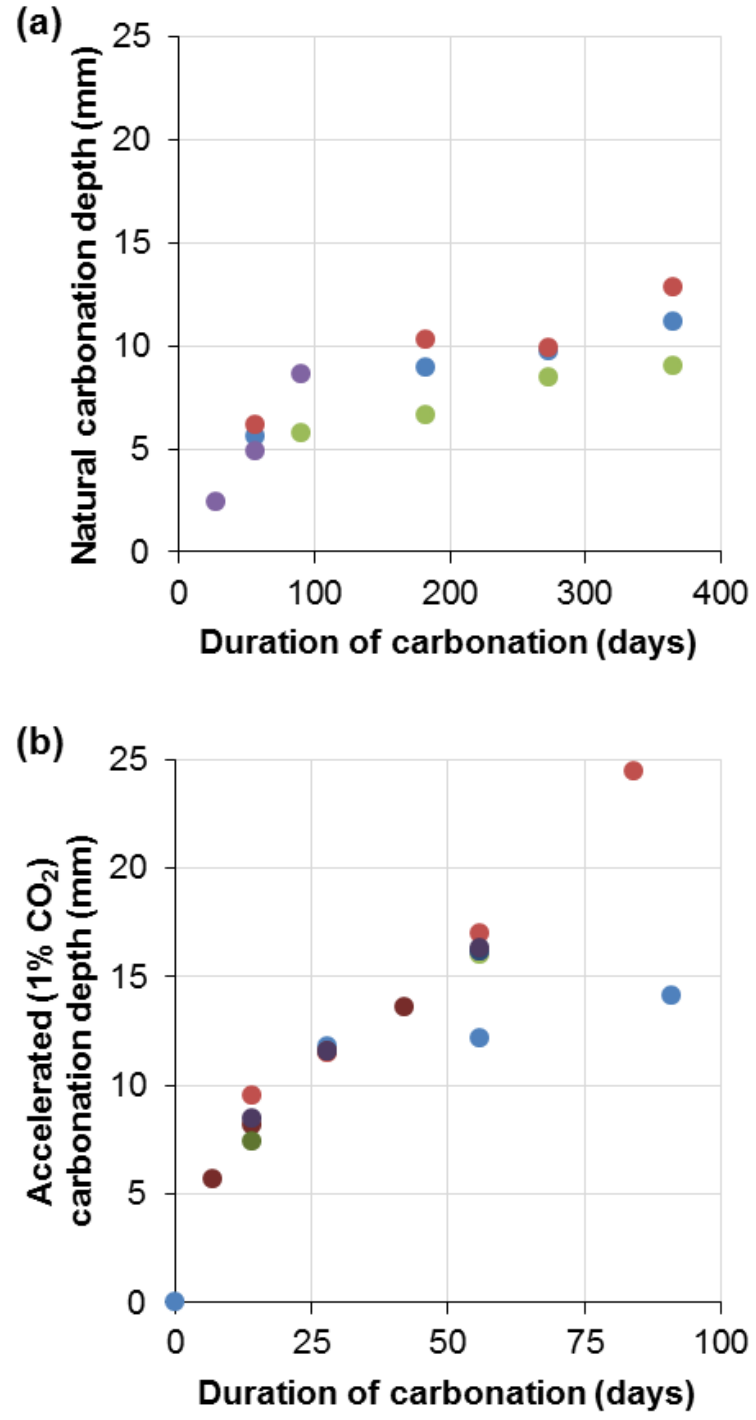

Fig. 4. Carbonation depths measured for the alkali-activated slag concrete designed for 'moderate' performance (S1b), under (a) natural and (b) accelerated $\left(1 \% \mathrm{CO}_{2}\right)$ conditions. As in Figure 1, each colour represents results reported from a particular laboratory.

The natural carbonation data may also show an initial 'skin' of carbonated material, as a non-zero carbonation depth at the start of the carbonation exposure (i.e. some carbonation taking place during casting or curing). This must be taken into consideration when fitting mathematical relationships to these data for prediction of long-term carbonation depths. Fig. 5 shows that if a model is fitted from a zero initial carbonation depth, this would lead to prediction of a significantly greater carbonation depth after several years in service, than if a non-zero initial carbonation depth is used. In Fig. 5, the data from Figure 4a (up to 1 year of natural carbonation) are re-plotted along with two simple power law models (carbonation dependent on the square root of time; assuming pure diffusion control). One model is fitted from an assumption of zero initial carbonation depth, and the other with an initial carbonation depth of 2.5 $\mathrm{mm}$. After 10 years, this corresponds to a difference of $\sim 8 \mathrm{~mm}$ in the predicted carbonation depth, which is very significant if the model is then to be used to predict service life of elements or structures. Thus, it is essential to correctly describe this early time period when formulating any service life prediction models for AAM concretes.

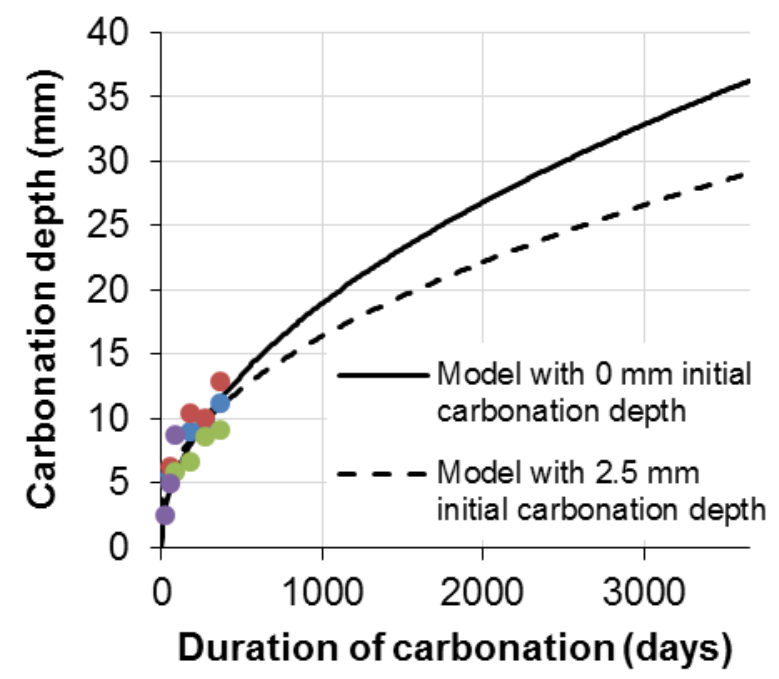

Fig. 5. Extrapolation of Fig. 4a to predict 10 years' natural corrosion, based on different assumptions about initial carbonation depth as marked, and assuming diffusion control of carbonation rate.

\subsection{Other tested modes of degradation}

The other areas of testing in the RILEM round-robin test found fewer participants and not such a richness of directly comparable data, but some conclusions can be drawn from the results that were compiled, as follows:

Immersion in sodium sulfate solution did not cause significant expansion or damage to any of the materials tested under any of the standardized testing regimes applied. Magnesium sulfate immersion caused some chemical degradation and loss of strength, but not expansion. In tests which measure dimensional stability of AAM concretes or mortars, the setting of the initial length (i.e. the zero point for expansion) needs detailed attention.

In alkali-silica reaction testing, the presence of very high concentrations of alkalis in AAM did not appear to induce any dangerous expansive reaction of commonly used aggregates - i.e., aggregates of 'normal' reactivity were not induced to become problematically reactive when used in AAM. When aggregates that are known to be problematically reactive in Portland cement concretes (e.g. Spratt crushed limestone) were used, some expansion was observed, but this was not beyond the expansion expected for blended Portland cement-based materials containing the same aggregates under the same test conditions.

Salt scaling tests applied to non-air entrained AAM concretes showed significant damage, as expected in the absence of air entrainment. Freeze-thaw testing without added salt gave less evident damage overall, but more investigation is needed to validate both materials and test methods in this area. 


\section{Conclusions}

The key outcome of the RILEM TC 247-DTA roundrobin testing programme is that further analysis and testing is required; it is not yet possible to provide definitive answers to the core questions posed, but the body of evidence and understanding in this area is rapidly growing in a direction that will support future standardisation efforts related to AAM. The selection and implementation of accelerated durability testing methods that are truly appropriate for modern concretes - whether alkali-activated, or high-volume blends with Portland cement - remains a work in progress. However, inter-laboratory testing is essential to validate methods so engineers can have confidence to use the testing results to underpin standardization. This is challenging and will not be achieved quickly, particularly when considering the multiple modes of attack and degradation that take place under truly realistic service environments [43], but is essential to the future development and uptake of sustainable, high-performing, durable infrastructure materials.

Regarding the specific test outcomes: overall, the intra-laboratory reproducibility of many of the tests considered is excellent, but inter-laboratory comparisons remain problematic. Longer-term testing is generally better than highly accelerated testing in terms of giving comparable results across different laboratories, but is also more time-consuming, and this time can also be expensive. We do not yet have the level of knowledge of test methods, or of their application to alkali-activated concretes, to encode particular performance levels in these tests into standards and then design materials to meet them. However, it may be an acceptable alternative if candidate materials are tested in parallel with concretes of known acceptable performance under similar exposure conditions, as long as the equivalence of performance under test conditions can be sufficiently well linked to equivalent performance in the field.

Some of the research leading to these results, in the laboratory of JLP, received funding from the European Research Council under the European Union's Seventh Framework Programme (FP/2007-2013) / ERC Grant Agreement \#335928. The work and insight of all members of RILEM TC 247-DTA who contributed to the design and conduct of round-robin testing are very gratefully acknowledged.

\section{References}

1. Cembureau, Activity Report 2016, available at https://cembureau.eu/media/1635/activity-report2016.pdf (2017)

2. J.G.J. Olivier, G. Janssens-Maenhout, J.A.H.W. Peters, J. Wilson, Long-term trend in global $\mathrm{CO}_{2}$ emissions: 2011 Report, PBL Netherlands Environmental Assessment Agency, The Hague, The Netherlands, available at http://www.pbl.nl/sites/default/files/cms/publicaties /C02\%20Mondiaal_\%20webdef_19sept.pdf (2011)

3. J.L. Provis, Adv. Appl. Ceram. 113, 472 (2014)
4. World Business Council for Sustainable Development_(WBCSD) Cement Sustainability Initiative (CSI), Cement Industry Energy and $\mathrm{CO}_{2}$ Performance - Getting the Numbers Right (GNR), available at http://wbcsdservers.org/wbcsd publications/cd_files/datas/business-solutions/ cement/pdf/Cement IndustryEnergyAnd $\% 20 \mathrm{CO} 2$ Performance.pdf (2009)

5. K.L. Scrivener, V.M. John, E.M. Gartner, Ecoefficient cements: Potential, economically viable solutions for a low- $\mathrm{CO}_{2}$, cement-based materials industry, Report of the United Nations Environment Programme, available at https://lmc.epfl.ch/files/content/users/184559/files/ 2016-UNEP\%20Report-Complete6.pdf (2016)

6. International Energy Agency (IEA), Greenhouse Gas R\&D Programme, Greenhous gas emissions from major industrial sources - III. Iron and steel production, Report Number $\mathrm{PH} 3 / 30$, available at http://www.ieaghg.org/docs/General_Docs/Reports /PH3-30\%20iron-steel.pdf (2000).

7. M.S. Imbabi, C. Carrigan, S. McKenna, Int. J. Sust. Built Environ. 1, 194 (2012)

8. B. Lothenbach, K. Scrivener, R.D. Hooton, Cem. Concr. Res. 41, 1244 (2011)

9. K. Scrivener, F. Martirena, S. Bishnoi, S. Maity, Cem. Concr. Res., in press (2018)

10. E. Gartner, T. Sui, Cem. Concr. Res., in press (2018)

11. J.L. Provis, Cem. Concr. Res., in press (2018)

12. R.D. Hooton, J.A. Bickley, Constr. Build. Mater. 67C, 422 (2014)

13. R. Wassermann, A. Katz, A. Bentur, Mater. Struct. 42, 973 (2009)

14. B.L. Damineli, V.M. John, Key Eng. Mater. 517, 342 (2012)

15. K.L. Scrivener, Indian Concr. J. 88, 11 (2014)

16. J.L. Provis, Front. Mater. 2, 31 (2015)

17. M.C.G. Juenger, F. Winnefeld, J.L. Provis, J.H. Ideker, Cem. Concr. Res. 41, 1232 (2011)

18. G. Habert, in: F. PachecoTorgal, L.F. Cabeza, J. Labrincha, A. DeMagalhaes (Eds.) Eco-Efficient Construction and Building Materials: Life Cycle Assessment 2014, 199 (2014)

19. S.A. Bernal, E.D. Rodríguez, A.P. Kirchheim, J.L. Provis, J. Chem. Technol. Biotechnol. 91, 2365 (2016)

20. M. Criado, X. Ke, J.L. Provis, S.A. Bernal, , in: H. Savastano Jr, J. Fiorelli, S.F. dos Santos (Eds.) Sustainable and Nonconventional Construction Materials using Inorganic Bonded Fiber Composites, Woodhead, Duxford, UK, 185 (2017)

21. J.S.J. Van Deventer, D.G. Brice, S.A. Bernal, J.L. Provis, in: L. Struble, J.K. Hicks (Eds.) Symposium on Geopolymer Binder Systems, ASTM Special Technical Publication STP 1566, ASTM International, San Diego, CA, 196 (2013)

22. E.S. Kavalerova, P.V. Krivenko, G. Rostovskaya, in: C. Shi, X. Shen (Eds.) Second International Conference on Advances in Chemically-Activated Materials (CAM'2014), RILEM, Changsha, China, 449 (2014) 
23. L.S.-C. Ko, I. Beleña, P. Duxson, E. Kavalerova, P.V. Krivenko, L.-M. Ordoñez, A. Tagnit-Hamou, F. Winnefeld, AAM concretes, in: J.L. Provis, J.S.J. van Deventer (Eds.) Alkali-Activated Materials: State-of-the-Art Report, RILEM TC 224$A A M$, Springer/RILEM, Dordrecht, 157 (2014)

24. J.S.J. van Deventer, R. San Nicolas, I. Ismail, S.A. Bernal, D.G. Brice, J.L. Provis, J. Sust. Cem.Based Mater. 4, 116 (2015)

25. J.L. Provis, in: A. Tagnit-Hamou (Ed.) $10^{\text {th }}$ ACI/RILEM International Conference on Cementitous Materials and Alternative Binders for Sustainable Concrete, ACI/RILEM, Montreal, Canada, CD-ROM Proceedings (2017)

26. C. Shi, P.V. Krivenko, D. Roy, Alkali-Activated Cements and Concretes, Taylor and Frances, New York (2006)

27. J.L. Provis, P. Duxson, E. Kavalerova , P.V. Krivenko, Z. Pan, F. Puertas , J.S.J. van Deventer, in: J.L. Provis, J.S.J. van Deventer (Eds.) AlkaliActivated Materials: State-of-the-Art Report, RILEM TC 224-AAM, Springer/RILEM, Dordrecht, 11 (2014)

28. British Standards Institute, BSI PAS 8820:2016, Construction materials - Alkali-activated cementitious material and concrete - Specification, London, UK (2016)

29. British Standards Institution, Concrete Complementary British Standard to BS EN 206-1 Part 2: Specification for constituent materials and concrete (BS 8500-2:2006+A1:2012), London, UK (2012)

30. European Committee for Standardization (CEN), Principles of the equivalent durability procedure (PD CEN/TR 16563:2013), Brussels, Belgium (2013)

31. European Committee for Standardization (CEN), Concrete: Specification, performance, production and conformity (EN 206:2013), Brussels, Belgium (2013)

32. J.L. Provis, Sixth International Conference on the Durability of Concrete Structures, Leeds, UK, 1820 July 2018, 1350 (2018)
33. Swiss Society of Engineers and Architects (SIA), Anforderungen an neue Zemente (Specifications for new cements), SIA Merkblatt MB 2049 (2014)

34. European Committee for Standardization (CEN), EN 197-1:2011, Cement. Part 1: Composition, specifications and conformity criteria for common cements, Brussels, Belgium (2011)

35. S.A. Bernal, J.L. Provis, D.G. Brice, A. Kilcullen, P. Duxson, J.S.J. van Deventer, Cem. Concr. Res. 42, 1317 (2012)

36. S.A. Bernal, V. Bílek, M. Criado, A. FernándezJiménez, E. Kavalerova, P.V. Krivenko, M. Palacios, A. Palomo, J.L. Provis, F. Puertas, R. San Nicolas, C. Shi, F. Winnefeld, in: J.L. Provis, J.S.J. van Deventer (Eds.) Alkali-Activated Materials: State-of-the-Art Report, RILEM TC 224-AAM, Springer/RILEM, Dordrecht, 223 (2014)

37. NordTest, Concrete, hardened: Accelerated chloride penetration (NT BUILD 443), Espoo, Finland (1995)

38. NordTest, Concrete, mortar and cement-based repair materials: Chloride migration coefficient from non-steady state migration experiments (NT BUILD 492), Espoo, Finland (1999)

39. ASTM International, Standard test method for electrical indication of concrete's ability to resist chloride ion penetration (ASTM C1202 - 17a), West Conshohocken, PA (2017)

40. A. Neville, Mater. Struct. 34, 14 (2001)

41. J.L. Provis, R.J. Myers, C.E. White, V. Rose, J.S.J. van Deventer, Cem. Concr. Res. 42, 855 (2012)

42. A. Aït-Mokhtar, R. Belarbi, F. Benboudjema, N. Burlion, B. Capra, M. Carcassès, J.B. Colliat, F. Cussigh, F. Deby, F. Jacquemot, T. de Larrard, J.F. Lataste, P. Le Bescop, M. Pierre, S. Poyet, P. Rougeau, T. Rougelot, A. Sellier, J. Séménadisse, J.M. Torrenti, A. Trabelsi, P. Turcry, H. YanezGodoy, Cem. Concr. Res. 45, 21 (2013)

43. E. Holt, M. Ferreira, H. Kuosa, M. Leivo, J. Chin. Ceram. Soc. 43, 1420 (2015) 